\title{
Synthesis and structural characterization of a novel peroxo bridged dinuclear cobalt(III) complex of succinimide showing three varieties of hydrogen bonding interactions
}

\author{
MURAT TAŞ ${ }^{\mathrm{a}, *}$ and ORHAN BÜYÜKGÜNGÖR ${ }^{\mathrm{b}}$ \\ ${ }^{a}$ Giresun University, Faculty of Art and Sciences, Department of Chemistry, 28049 Giresun, Turkey \\ ${ }^{\mathrm{b}}$ Ondokuz Mayıs University, Faculty of Art and Sciences, Department of Physics, Samsun, Turkey \\ e-mail: murat.tas@giresun.edu.tr
}

MS received 4 June 2008; revised 9 April 2009

\begin{abstract}
The reaction of aqueous cobaltous nitrate hexahydrate with the anion of succinimide (sucH) in the presence of excess ethylenediamine (en) in air results in the formation of a dinuclear complex $\mu$-peroxo-bis[bis(ethylenediamine)succinimidato-cobalt(III)] dinitrate dihydrate, 1, in good yield. Compound 1 was characterized by elemental analysis, IR, visible spectra and magnetic susceptibility studies. The explosive nature of $\left[\mathrm{Co}(\mathrm{en})_{2}(\mathrm{suc})\left(\mu-\mathrm{O}_{2}\right) \mathrm{Co}(\mathrm{en})_{2}(\mathrm{suc})\right]\left(\mathrm{NO}_{3}\right)_{2} \cdot 2 \mathrm{H}_{2} \mathrm{O}, \mathbf{1}$, precluded its thermal characterization. Compound 1 crystallises in the monoclinic space group $P 2_{1} / c$ and a half of the molecule, constitutes its asymmetric unit. In the centrosymmetric dinuclear complex 1, two Co(III) centres are linked by a planar peroxide bridge. Each cobalt atom is surrounded by four nitrogen atoms of ethylenediamine ligands, a nitrogen atom of succinimidato anion and an oxygen atom of peroxo bridge resulting in a slightly distorted $\left\{\mathrm{CoN}_{5} \mathrm{O}\right\}$ octahedron. Due to steric hindrance between the two $\mathrm{Co}(\mathrm{III})$ centres, the peroxide bridge is planar with a $\mathrm{Co}-\mathrm{O}-\mathrm{O}-\mathrm{Co}$ torsion angle of $180^{\circ}$. The dinuclear complex cation, the nitrate anion and the lattice water are involved in three varieties of $\mathrm{H}$-bonding interactions namely $\mathrm{N}-\mathrm{H} \cdots \mathrm{O}, \mathrm{O}-\mathrm{H} \cdots \mathrm{O}$ and $\mathrm{C}-\mathrm{H} \cdots \mathrm{O}$.
\end{abstract}

Keywords. Ethylenediamine; succinimide; succinimidato; peroxo bridge; dinuclear; H-bonding.

\section{Introduction}

It is well known that complexation of dioxygen plays a vital role in many biological systems. Extensive research has focused on the coordination chemistry of naturally occurring dioxygen complexes, i.e. haemoglobin, haemerythrin, haemocyanin and their model compounds. ${ }^{1}$ Many biological reactions involving dioxygen are very fast with synthetic caged dioxygen carriers. Cobalt(II) complexes of polyamines, amino acids, and dipeptide ligands containing dicobalt, $\mu$-peroxo or, $\mu$-superoxo-bridged derivatives have been studied extensively, because of their applicability to biochemical systems. ${ }^{2}$ Many are available in the literature to indicate that the stabilities of dioxygen complexes increase with an increase in the number of basic nitrogens. ${ }^{3}$ In these complexes, the binding of oxygen is accompanied, in many cases, by the transfer of electrons from the metal center to the oxygen molecule, and thus the

*For correspondence oxidation state of the metal atom changes. ${ }^{4}$ In view of this, peroxo-bridged dicobalt complexes are often regarded as models for biological oxygen carriers. $^{5}$

The pyrrolidine skeleton occurs in many families of biologically important compounds. Several succinimide (pyrrolidine-2,5-dione) derivatives are important in biology due to their antiepileptic, anticonvulsive, fungicidal and other pharmacological properties. ${ }^{6}$ Since its first description in 1905, Yamada et al. synthesized the mixed ligand $\mathrm{Cu}(\mathrm{II})$ succinimide (sucH) complexes with some alkylamines (from methylamine to $n$-butylamine) to investigate electronic spectral features. Slabbert et al prepared some $\mathrm{Cu}$ (II) and $\mathrm{Ni}(\mathrm{II})$ succinimide complexes with different alkylamines to study the vibrational spectra of the complexes. ${ }^{7,8}$ Various aliphatic amine derivatives of metal(II)-succinimidato complexes have been synthesized and recently some $\mathrm{Cu}(\mathrm{II})$ - succinimidato complexes have been characterized by X-ray diffraction. ${ }^{9-17}$ The literature survey shows that the copper complexes of succinimide 
Table 1. Crystal data and structure refinement for compound 1.

\begin{tabular}{ll}
\hline Empirical formula & {$\left[\mathrm{C}_{16} \mathrm{H}_{40} \mathrm{Co}_{2} \mathrm{~N}_{10} \mathrm{O}_{6}\right] \cdot 2\left(\mathrm{NO}_{3}\right) \cdot 2\left(\mathrm{H}_{2} \mathrm{O}\right)$} \\
Formula weight $\left(\mathrm{g} \mathrm{mol}^{-1}\right)$ & $296(2)$ \\
Temperature $(\mathrm{K})$ & $0 \cdot 71073$ \\
Wavelength $(\mathrm{A})$ & Monoclinic \\
Crystal system & $P 2_{1} / c$ \\
Space group & \\
Unit cell dimensions $\left(\AA,^{\circ}\right)$ & $9 \cdot 4769(4) ; 16 \cdot 2143(8) ; 12 \cdot 7866(6)$ \\
$a ; b ; c$ & $130 \cdot 984(3)$ \\
$\beta$ & $1483 \cdot 22(14)$ \\
Volume $\left(\AA^{3}\right)$ & 2 \\
$Z$ & $1 \cdot 671$ \\
Density (calcd.) $\left(\mathrm{g} / \mathrm{cm}^{3}\right)$ & $1 \cdot 203$ \\
Absorption coefficient $\left(\mathrm{mm}^{-1}\right)$ & 780 \\
$F(000)$ & $0 \cdot 32 \times 0 \cdot 50 \times 0 \cdot 52$ \\
Crystal size $\left(\mathrm{mm}{ }^{3}\right)$ & $2 \cdot 5-26 \cdot 5^{\circ}$ \\
Theta range for data collection $\left(^{\circ}\right)$ & $-11 \rightarrow 8 ; 0 \rightarrow 20 ; 0 \rightarrow 16$ \\
Index ranges & 12116 \\
Reflections collected & 3061 \\
Independent reflections $\left(R_{\text {int }}\right)$ & $2 \cdot 11-28$ \\
Completeness to theta & Full-matrix least-squares on $F^{2}$ \\
Refinement method & $12116 / 2636 / 0 \cdot 000$ \\
Data/restraints/parameters & $1 \cdot 08$ \\
Goodness-of-fit on $F^{2}$ & $0 \cdot 0330$ \\
Final $R$ indices $[I>2 \sigma(I)]$ & $0 \cdot 0849$ \\
$R$ indices (all data) & 0 \\
Extinction coefficient & $-0 \cdot 82,0 \cdot 37$ \\
Largest diff. peak and hole $\left(\mathrm{e} \AA^{-3}\right)$ &
\end{tabular}

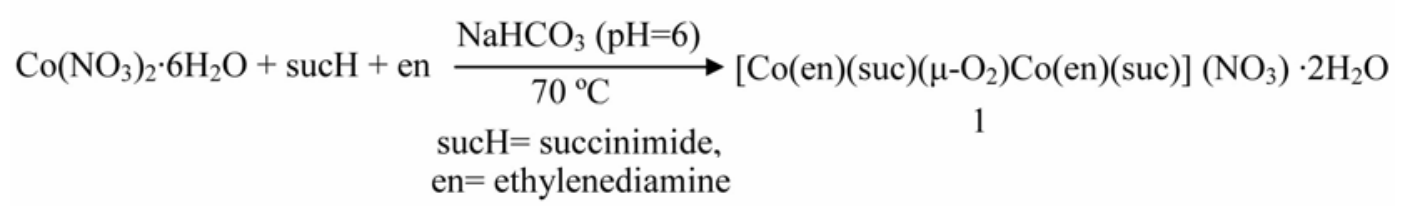

Scheme 1.

have been studied extensively, while there is no report on cobalt complexes of succinimide.

Ethylenediamine (en), its salts, and its derivatives are frequently found in drugs as well as biologically important molecules. Representative drug classes containing this moiety include the antihistamine, pyrilamine and chlorcyclazine; the ganglionic blocking agent, chlorisondamine; the antihelmintic, piperizine, and the antiarrhythmic agent, procainamide. In each of these compounds, the ethylenediamine portion plays an essential role in the biological activities of these molecules. The structural features of this moiety that confer biological activity are the electron distribution among the atoms and the stereochemistry. ${ }^{18}$ In the present report, we describe the synthesis, spectral and structural characterization of a peroxo bridged dinuclear Co(III) complex con- taining $\mathrm{N}$-donor ligands like en and succinimidato anion bonded to $\mathrm{Co}(\mathrm{III})$.

\section{Experimental}

\subsection{Material and measurements}

All chemicals used in this work were of reagentgrade commercial materials. FT-IR spectra (4000$400 \mathrm{~cm}^{-1}$ ) were recorded on a Perkin-Elmer-Spectrum 100 FT-IR spectrophotometer with samples prepared as $\mathrm{KBr}$ pellets. Magnetic susceptibilities were measured using a Sherwood scientific MX1 model Gouy magnetic balance at room temperature. UVVis spectra were recorded with a PG-T80 + UV-Vis spectrometer. $\mathrm{pH}$ was measured using EutechCyberscan $510 \mathrm{pH}-$ meter. Elemental analysis for $\mathrm{C}$, 


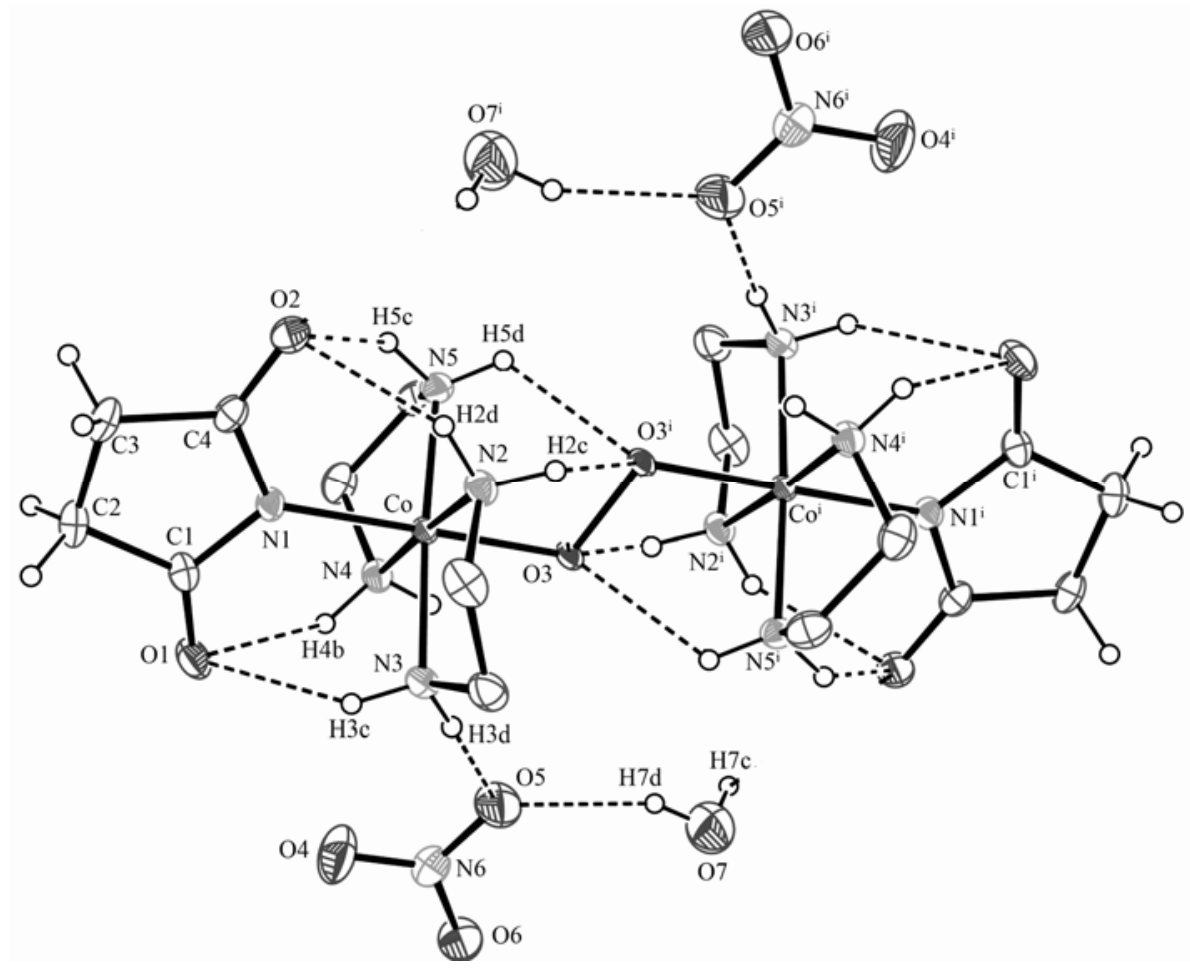

Figure 1. An ORTEP view of compound 1 showing the crystallographic labelling. Ellipsoids are drawn at $30 \%$ probability level and some $\mathrm{H}$ atoms are omitted for clarity. Intramolecular hydrogen bonding is shown by broken lines. (Symmetry code: $\mathrm{I}=[1-x, 1-y, 1-z]$ ).

$\mathrm{H}$ and $\mathrm{N}$ were performed using a Carlo Erba 1106 microanalyser.

\subsection{Synthesis of $\mu$-peroxo-bis[bis(ethylenediamine) succinimidato-cobalt(III)] dinitrate dihydrate 1}

To a solution of $\mathrm{Co}\left(\mathrm{NO}_{3}\right)_{2} \cdot 6 \mathrm{H}_{2} \mathrm{O}(2.91 \mathrm{~g}, 10 \mathrm{mmol})$ in water $(20 \mathrm{ml})$, succinimide $(1.00 \mathrm{~g}, 10.1 \mathrm{mmol})$ was added and the reaction mixture was heated to $70^{\circ} \mathrm{C}$. The $\mathrm{pH}$ was adjusted to 6 by adding $1 \% \mathrm{Na}$ $\mathrm{HCO}_{3}$ solution. An excess of ethylenediamine (approximately $2 \mathrm{ml}$ ) was added to the hot solution and stirred at $70^{\circ} \mathrm{C}$ for $30 \mathrm{~min}$. The colour of the solution changed from red violet to brown. The reaction mixture was slowly cooled to room temperature and left undisturbed in open air. After several days darkbrown crystals were collected, rinsed with water, followed by cold ethanol. Yield of dry product (3.4 g, 45\%).

Caution: The complex explodes when heating and hence not studied by thermal method.

Analysis: Calc. for $\mathrm{C}_{16} \mathrm{H}_{44} \mathrm{Co}_{2} \mathrm{~N}_{12} \mathrm{O}_{14}: \mathrm{C}, 25.74 ; \mathrm{H}$, $5.94 ; \mathrm{N}, 22.52 \%$. Found: C, 25.77; H, 5.90; N, $22.57 \%$.
IR ( $\mathrm{KBr}, \bar{v}, \mathrm{~cm}^{-1}$ selected peaks): $3437 w, 3300 \mathrm{~m}$, $3235 \mathrm{~m}, 1884 \mathrm{~m}, 1775 \mathrm{w}, 1455 \mathrm{~m}, 1430 \mathrm{~m}, 886 \mathrm{~m}$, $532 \mathrm{~m}$.

UV-Vis : $\left[\lambda_{\max }\right.$ in $\left.\mathrm{nm},\left(\varepsilon, \mathrm{dm}^{3} \mathrm{~mol}^{-1} \mathrm{~cm}^{-1}\right)\right]: 400$ (2000) and 800 (50) (in $\mathrm{H}_{2} \mathrm{O}$ ).

\subsection{X-ray crystallography}

Intensity data were collected on an Image Plate diffraction System (IPDS 2) from STOE using graphitemonochromated Mo-K $\alpha$ radiation. Data collection and cell refinement was performed using X-Area $;{ }^{19}$ while X-Red $32 ;{ }^{19}$ was used for data reduction. The structure was solved using Sir2004; ${ }^{20}$ and refinement was done against $F^{2}$ using SHELXL-97. ${ }^{21}$ OrtepIII $^{22}$ was used for molecular graphics while the publication material was prepared using Wingx. ${ }^{23}$ All nonhydrogen atoms were refined anisotropically. The $\mathrm{C}-\mathrm{H}$ hydrogen atoms were positioned with idealized geometry and refined using a riding model. The $\mathrm{N}$ $-\mathrm{H}$ and $\mathrm{O}-\mathrm{H}$ hydrogen atoms were located in the difference map, their bond lengths set to ideal values and afterwards they were refined isotropic using a riding model. The technical details of data acquisi- 
Table 2. Selected bond lengths $(\AA)$ and angles $\left({ }^{\circ}\right)$.

\begin{tabular}{|c|c|c|c|}
\hline \multicolumn{4}{|l|}{ Bond distances } \\
\hline Col-O3 & $1.897(1)$ & $\mathrm{N} 1-\mathrm{C} 1$ & $1 \cdot 374(2)$ \\
\hline Col-N1 & $1.974(2)$ & $\mathrm{N} 1-\mathrm{C} 4$ & $1 \cdot 371(2)$ \\
\hline Col-N2 & $1.938(2)$ & $\mathrm{O} 1-\mathrm{C} 1$ & $1 \cdot 225(3)$ \\
\hline Col-N3 & $1.957(2)$ & $\mathrm{O} 2-\mathrm{C} 4$ & $1.231(4)$ \\
\hline Col-N4 & $1.944(2)$ & $\mathrm{O} 3-\mathrm{O}^{\mathrm{i}}$ & $1.499(2)$ \\
\hline Col-N5 & $1.949(2)$ & & \\
\hline \multicolumn{4}{|l|}{ Bond angles } \\
\hline $\mathrm{Co} 1-\mathrm{O} 3-\mathrm{O}^{\mathrm{i}}$ & $109 \cdot 72(12)$ & N2-Co1-N3 & $85 \cdot 79(7)$ \\
\hline O3-Co1-N1 & $179 \cdot 35(6)$ & N2-Co1-N4 & $177 \cdot 48(7)$ \\
\hline $\mathrm{O} 3-\mathrm{Co} 1-\mathrm{N} 2$ & $89 \cdot 33(6)$ & N2-Co1-N5 & $95 \cdot 77(7)$ \\
\hline O3-Co1-N3 & $88.09(6)$ & N3-Co1-N4 & $92 \cdot 42(7)$ \\
\hline O3-Co1-N4 & $88 \cdot 82(6)$ & N3-Co1-N5 & $175 \cdot 55(7)$ \\
\hline O3-Co1-N5 & $87 \cdot 77(6)$ & N4-Co1-N5 & $85 \cdot 88(7)$ \\
\hline N1-Col-N2 & $91 \cdot 32(7)$ & $\mathrm{N} 1-\mathrm{C} 1-\mathrm{C} 2$ & $111 \cdot 29(18)$ \\
\hline N1-Co1-N3 & $91.89(7)$ & $\mathrm{N} 1-\mathrm{C} 4-\mathrm{C} 3$ & $111 \cdot 48(18)$ \\
\hline N1-Co1-N4 & $90.53(7)$ & $\mathrm{O} 1-\mathrm{C} 1-\mathrm{N} 1$ & $124 \cdot 39(19)$ \\
\hline N1-Co1-N5 & $92 \cdot 24(7)$ & $\mathrm{O} 2-\mathrm{C} 4-\mathrm{N} 1$ & $124 \cdot 18(19)$ \\
\hline
\end{tabular}

i: $1-x, 1-y, 1-z$

tion and some selected refinement results are summarised in table 1 .

\section{Results and discussion}

\subsection{Synthesis and spectral studies}

The reaction of a Co(II) salt in air in the presence of $\mathrm{N}$-donor ligands resulting in the formation of $\mathrm{Co}$ (III) complexes is well documented in the literature. Thus in the present work the reaction of cobaltous nitrate with sucH and en resulted in the formation of the peroxo bridged title compound $\mathbf{1}$ in good yield (scheme 1). The formula of $\mathbf{1}$ was arrived at based on its analytical, spectral and structural data. Based on analytical data, charge considerations, 1 was formulated as a dinuclear Co(III) compound. The observed diamagnetic nature of $\mathbf{1}$ is consistent with the presence of Co(III). The UV-Vis. spectrum in water showed a charge transfer band at $400 \mathrm{~nm}$ and a band at $800 \mathrm{~nm}$ assignable for a $d \rightarrow d$ transition as expected for octahedrally surrounded Co(III) ions. Interestingly, the weak signal at $800 \mathrm{~nm}$ disappeared after $15 \mathrm{~min}$ in water and DMSO solutions. This result can be attributed to the decomposition of 1 in solution.

The IR spectrum of pure sucH shows a signal at $3375 \mathrm{~cm}^{-1}$, assignable to the $\mathrm{N}-\mathrm{H}$ vibration and a $\mathrm{C}=\mathrm{O}$ peak at $1775 \mathrm{~cm}^{-1}$. In the IR spectrum of 1 , no signal is observed at around $3375 \mathrm{~cm}^{-1}$ indicating the presence of sucH in its anionic (suc). This is fur- ther supported by the shifting of the $\mathrm{C}-\mathrm{N}$-vibration of sucH from 1430 to $1455 \mathrm{~cm}^{-1}$. The $v(\mathrm{C}=\mathrm{O})$ signal remains unshifted indicating that the $\mathrm{C}=\mathrm{O}$ unit is non-coordinated to the metal. ${ }^{7,8,17}$ The peaks at 3300 and $3235 \mathrm{~cm}^{-1}$ are assigned to the vibrations for the $\mathrm{NH}_{2}$ groups of en. These results are in agreement with previous reports. ${ }^{7-12,16-17}$ The presence of water in 1 is evidenced by the strong signal at $3437 \mathrm{~cm}^{-1}$. The observed signals at 886 and $532 \mathrm{~cm}^{-1}$ are assigned for the vibrations of the peroxo moiety which is in accordance with literature reports ${ }^{24,25}$.

\subsection{Crystal structure description}

Compound 1 crystallises in the centrosymmetric monoclinic space group $P 2_{1} / c$ and its structure consists of a complex cation of 1 namely $\mu$-peroxobis [succinimidato-bis(ethylenediamine)cobalt(III) $]^{2+}$ located on an inversion centre, a nitrate anion and a lattice water (figure 1). The centre of inversion is situated at the midpoint of the $\mathrm{O}-\mathrm{O}$ bond with the $(\mathrm{O}-\mathrm{O})^{2-}$ functioning as a bridge between the symmetry related $\mathrm{Co}$ (III) ions. In view of this special position for the complex cation a half of the molecule, constitutes its asymmetric unit. Each cobalt atom is surrounded in an octahedral fashion by four nitrogen atoms from two en ligands, a nitrogen atom of an anioinic suc ligand and an oxygen atom of peroxobridge resulting in a $\left\{\mathrm{CoN}_{5} \mathrm{O}\right\}$ octahedron. The trans $\mathrm{O}-\mathrm{Co}-\mathrm{N}$ and $\mathrm{N}-\mathrm{Co}-\mathrm{N}$ angles are very close to the ideal value and vary between 175.55(7) and 
Table 3. Hydrogen bond geometry for compound 1.

\begin{tabular}{|c|c|c|c|c|}
\hline $\mathrm{D}-\mathrm{H} \cdots \mathrm{A}$ & D-H & $\mathrm{H} \cdots \mathrm{A}$ & $\mathrm{D} \cdots \mathrm{A}$ & $\mathrm{D}-\mathrm{H} \cdots \mathrm{A}$ \\
\hline $\mathrm{N} 2-\mathrm{H} 2 \mathrm{~d} \cdots \mathrm{O} 2$ & 0.90 & $2 \cdot 14$ & $2 \cdot 886(2)$ & 139.9 \\
\hline $\mathrm{N} 3-\mathrm{H} 3 \mathrm{c} \cdots \mathrm{O} 1$ & 0.90 & $2 \cdot 33$ & $2 \cdot 997(2)$ & $130 \cdot 6$ \\
\hline $\mathrm{N} 4-\mathrm{H} 4 \mathrm{~b} \cdots \mathrm{O} 1$ & 0.90 & $2 \cdot 13$ & $2 \cdot 852(2)$ & $136 \cdot 8$ \\
\hline N4-H4a $\cdots O 5$ & 0.90 & $2 \cdot 71$ & $3 \cdot 272(3)$ & $121 \cdot 9$ \\
\hline $\mathrm{N} 5-\mathrm{H} 5 \mathrm{c} \cdots \mathrm{O} 2$ & 0.90 & $2 \cdot 35$ & $3 \cdot 041(2)$ & $133 \cdot 4$ \\
\hline $\mathrm{N} 3-\mathrm{H} 3 \mathrm{~d} \cdots \mathrm{O} 5$ & $0 \cdot 90$ & $2 \cdot 15$ & $3 \cdot 036(3)$ & $166 \cdot 7$ \\
\hline $\mathrm{O} 7-\mathrm{H} 7 \mathrm{~d} \cdots \mathrm{O} 5$ & $0.822(9)$ & $2 \cdot 134(12)$ & $2 \cdot 905(4)$ & $156(2)$ \\
\hline $\mathrm{N} 2-\mathrm{H} 2 \mathrm{c} \cdots \mathrm{O} 6^{\mathrm{ii}}$ & 0.90 & $2 \cdot 47$ & $3 \cdot 142(3)$ & 131.7 \\
\hline $\mathrm{C} 3-\mathrm{H} 3 \mathrm{~b} \cdots \mathrm{O} 6^{\mathrm{iii}}$ & 0.97 & 2.69 & $3 \cdot 639(3)$ & $166 \cdot 9$ \\
\hline $\mathrm{C} 2-\mathrm{H} 2 \mathrm{a} \cdots \mathrm{O} 5^{\mathrm{iii}}$ & 0.97 & 2.76 & $3 \cdot 602(3)$ & 145.9 \\
\hline $\mathrm{N} 2-\mathrm{H} 2 \mathrm{c} \cdots \mathrm{O} 3^{\mathrm{i}}$ & 0.90 & $2 \cdot 16$ & $2 \cdot 774(2)$ & $124 \cdot 5$ \\
\hline $\mathrm{N} 5-\mathrm{H} 5 \mathrm{~d} \cdots \mathrm{O}^{\mathrm{i}}$ & 0.90 & $2 \cdot 17$ & $2 \cdot 750(2)$ & $122 \cdot 0$ \\
\hline $\mathrm{N} 4-\mathrm{H} 4 \mathrm{a} \cdots \mathrm{O} 6^{\mathrm{iv}}$ & $0 \cdot 90$ & $2 \cdot 26$ & $3.039(3)$ & $144 \cdot 1$ \\
\hline $\mathrm{O} 7-\mathrm{H} 7 \mathrm{c} \cdots \mathrm{O} 4^{\mathrm{iv}}$ & $0 \cdot 816(9)$ & $2 \cdot 528(18)$ & $3 \cdot 171(4)$ & $137(2)$ \\
\hline $\mathrm{N} 5-\mathrm{H} 5 \mathrm{c} \cdots \mathrm{O} 1^{\mathrm{v}}$ & 0.90 & $2 \cdot 48$ & $3 \cdot 074(2)$ & $124 \cdot 0$ \\
\hline $\mathrm{C} 3-\mathrm{H} 3 \mathrm{a} \cdots \mathrm{O} 5^{\mathrm{v}}$ & 0.97 & 2.79 & $3 \cdot 726(3)$ & $162 \cdot 1$ \\
\hline $\mathrm{C} 2-\mathrm{H} 2 \mathrm{~b} \cdots \mathrm{O} 6^{\mathrm{v}}$ & 0.97 & 2.76 & $3.632(3)$ & $150 \cdot 1$ \\
\hline $\mathrm{N} 3-\mathrm{H} 3 \mathrm{c} \cdots \mathrm{O} 2^{\mathrm{vi}}$ & 0.90 & $2 \cdot 54$ & $3 \cdot 157(2)$ & $126 \cdot 3$ \\
\hline
\end{tabular}

i: $1-x, 1-y, 1-z$; ii: $1+x, y, z$; iii: $1-x, 1 / 2+y, 3 / 2-z$; iv: $-x, 1-y, 1-z$; v: $x$, $3 / 2-y,-1 / 2+z ;$ vi: $x, 3 / 2-y, 1 / 2+z$

$179.35(6)^{\circ}$ while the cis $\mathrm{O}-\mathrm{Co}-\mathrm{N}$ and $\mathrm{N}-\mathrm{Co}-\mathrm{N}$ angles range from $85.88(7)$ to $95 \cdot 77(7)^{\circ}$ indicating a distorted octahedron. The succinimide rings exhibit an approximately planar structure and are perpendicular to the $\mathrm{Co}-\mathrm{N} 4$ equatorial plane formed by four nitrogen atoms of two en ligands, with the largest deviation from the plane being that of atom $\mathrm{C} 2$ $[0.035(3) \AA]$. The observed bond angles of suc anion indicate the presence of an anionic suc and also electron delocalization in the $\pi$-conjugated system (table 2). ${ }^{11,17}$

The two en ligands in the asymmetric unit are in the $\delta \delta$ conformation. The $\mathrm{Co}-\mathrm{N}_{\mathrm{en}}$ bond lengths are found as 1.938(3), 1.957(2), 1.949(2) and 1.944(2) $\AA$ (table 2). ${ }^{26}$ The short distances across the bridge were those of $\mathrm{C} 6 \cdots \mathrm{C} 8^{\mathrm{i}}$ and $\mathrm{C} 8 \cdots \mathrm{C} 6^{\mathrm{i}}$, and are both $3.83 \AA$. This is less than twice the van der Waals radius of $\mathrm{C}-\mathrm{H}(2.0 \AA)$ in the synthesized complex and the suc and en ligands have trans-configuration with respect to the $\mu$-peroxo bridge.

For the charge balance, +2 charges on the binuclear cations require that the $\mathrm{O}_{2}$-bridge is a peroxide group. Due to the steric hindrance between the two +3 charged $\mathrm{Co}$ (III) centres, the peroxide bridge is planar with a $\mathrm{Co}-\mathrm{O}-\mathrm{O}-\mathrm{Co}$ torsion angle $180^{\circ}$. The O-O distance in bridge for $\mathbf{1}$ is 1.499(2) $\AA$ and is comparable with the reported values for $\mathrm{O}-\mathrm{O}$ bond in $\mu$-peroxo-bis[nitro-bis(ethylenediamine) cobalt(III) $]^{2+}$ [1.529(9) $\AA], \quad \mathrm{H}_{2} \mathrm{O}_{2} \quad(1.47-1.49 \AA)$ and $\mathrm{BaO}_{2}$ $(1.49 \AA) .{ }^{22}$ The $\mathrm{Co}-\mathrm{O}$ distance of $1.897(1) \AA$ is slightly longer than that found in $\mu$-peroxo-bis[nitrobis(ethylenediamine)cobalt(III) $]^{2+}[1 \cdot 887(6) \AA] .{ }^{22}$

The $\mathrm{Co}-\mathrm{N}_{\text {succin }}$ bond length is 1.974(2) $\AA$, and it is slightly longer than that in $\mu$-peroxo-bis[nitrobis(ethylenediamine)cobalt(III) $]^{2+}$ with a $\mathrm{Co}-\mathrm{N}_{\text {nitro }}$ distance of 1.940(8) $\AA^{26,27}$

A non-planar arrangement (the $\mathrm{Co}-\mathrm{O}-\mathrm{O}-\mathrm{Co}$ torsion angle $<180^{\circ}$ ) occurs only when the charges on the two centres are neutralized by extensively hydrogen bonded counter ions according to Fritch. ${ }^{28}$ When the $\mu$-peroxo-bis[pentaamminecobalt(III) $]^{4+}$ ion is crystallized as the thiocyanate salt, ${ }^{28}$ the cation participates in only two hydrogen bonds, and the peroxo bridge is planar. In the sulphate salt of the same cation, however, nearly all the amine hydrogen atoms participate in hydrogen bonds, effectively neutralizing the charges on the cobalt centres, and the peroxo-bridge has a dihedral angle of $146^{\circ} .^{28}$ The $\mu$-peroxo-bis[(ethylenediamine)(diethylenetriamine) cobalt(III) $]^{4+}$ cationic complex charge balanced by perchlorate counter anions, exhibits six hydrogen bonds, four of which are intramolecular. Based on this observation it was reported that perchlorate counter ions were isolated from the cation and were thus ineffective in neutralizing the concentration of charge; leading to a planar peroxide bridge. ${ }^{28}$ Interestingly the planar arrangements (the $\mathrm{Co}-\mathrm{O}-\mathrm{O}-$ Co torsion angle $=180^{\circ}$ ) were explained as a result of steric hindrance by Shibahara in $\mu$-peroxobis [nitro-bis(ethylenediamine) cobalt(III) $]^{2+}$ cation 


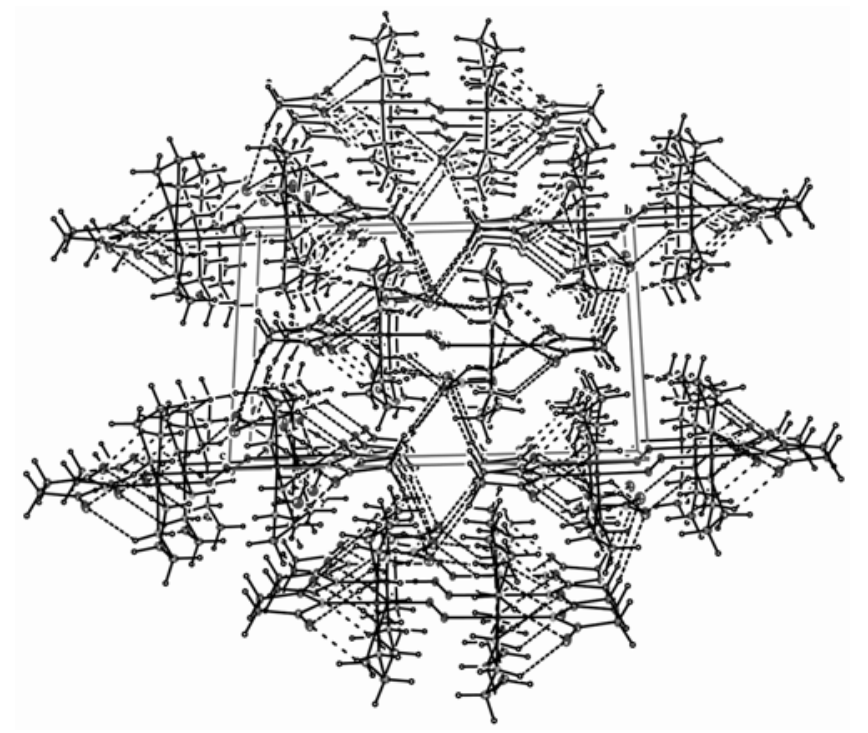

Figure 2. A view of crystal packing diagram of 1. Hbonds are shown in broken lines.

(nitrate was counter ion, and two hydrogen bonds were observed) and a similar arrangement was reported in $\mu$-peroxo-bis[acetonitrile-bis(ethylenediamine)-cobalt(III) $]^{4+}$ (tetratriflate was counter ion with two hydrogen bonds). ${ }^{26,27}$ The planar arrangement in $\mu$-peroxo-bis[nitro-bis(ethylenediamine) cobalt(III) $]^{2+}$ and the complex 1 , in which the charges on the cobalt centres are compensated by negatively charged anionic ligands like nitro and succinimidato anion, can be attributed to the steric hindrance to peroxo bridges.

An analysis of the crystal structure reveals that the dinuclear complex cation, the nitrate anion and the lattice water are involved in several $\mathrm{H}$-bonding interactions many of which are intramolecular (figure 1). All the oxygen atoms in 1 namely $\mathrm{O} 1, \mathrm{O} 2$ from suc, $\mathrm{O} 3$ of bridging peroxide, $\mathrm{O} 4, \mathrm{O} 5$ and $\mathrm{O} 6$ of nitrate and $\mathrm{O} 7$ of lattice water function as $\mathrm{H}$ acceptors while the $\mathrm{H}$ atoms attached to the amine groups of en, $\mathrm{H}$ atoms of lattice water and $\mathrm{H}$ atoms attached to $\mathrm{C} 2$ and $\mathrm{C} 3$ of suc ligand function as $\mathrm{H}-$ donors resulting in three varieties of $\mathrm{H}$-bonding interactions namely $\mathrm{N}-\mathrm{H} \cdots \mathrm{O}, \mathrm{O}-\mathrm{H} \cdots \mathrm{O}$ and $\mathrm{C}-\mathrm{H} \cdots \mathrm{O}$ and the geometrical details of these weak interactions are given in table 3 .

The H-bonding network is extended along $a$ axis with the aid of $\mathrm{N} 2-\mathrm{H} 2 \mathrm{c} \cdots \mathrm{O} 6$.

The complex molecules extend along the $b$ axis via $\mathrm{H}$-bonding to each other with the aid of the weak $\mathrm{C}-\mathrm{H} \cdots \mathrm{O}$ interactions (table 3 ). These hydrogen bonds form rings, which appear like a cube and extend along the three axes and can be described as $R_{2}^{2}(7)$ in Etter's notation. ${ }^{29}$ A view of the crystallographic packing of compound 1 showing its supramolecular architecture is displayed in figure 2 .

\section{Conclusions}

In the present report we have described the synthesis, spectral characteristics and structural features of a new peroxo bridged dinuclear Co(III) compound showing three varieties of $\mathrm{H}$-bonding interactions.

\section{Supplementary material}

Crystallographic data (excluding structure factors) have been deposited with the Cambridge Crystallographic Data Centre as the supplementary publication No. CCDC 682427. Copies of the data can be obtained, free of charge, on application to CCDC, 12 Union Road, Cambridge CB2 1EZ, UK (fax: +441223-336033 or e-mail: deposit@ ccdc.cam.ac.uk

\section{Acknowledgements}

This study was supported in part by a grant from TUBITAK (The Scientific and Technical Research Council of Turkey) (TBAG/HD 106T195 to Murat TAŞ).

\section{References}

1. Ortego J D and Seymour M 1982 Polyhedron 121

2. Macarthur R, Sucheta A, Chong F F S and Einarsdottir O 1995 Proc. Natl. Acad. Sci. USA 928105

3. Martell E, Motekaitis R J, Rockcliffe D, Menif R and Ngwenya P M 1994 Pure and Appl. Chem. 66859

4. Abakumov G A, Poddel'sky A I, Grunova E V, Cherkasov V K, Fukin G K, Kurskii Y A and Abakumova L G 2005 Angew. Chem. Int. Ed. 44 2767

5. Aires V V E, Zaccaron C M, Neves A and Szpoganicz B 2003 Inorg. Chim. Acta 35382

6. Argay G, Fábián L and Kálmán A 1999 Croatica Chemica Acta 72551

7. Yamada S and Miki S 1963 Bull. Chem. Soc. Jpn. 36 680

8. Slabbert N P and Thornton D A 1971 J. Inorg. Nucl. Chem. 332933

9. Akitsu T, Komorita S and Tamura H 2003 Inorg. Chim. Acta 34825

10. Akitsu T and Komorita S 2002 Bull. Chem. Soc. Jpn. 75767 
11. Akitsu T, Komorita S and Kushi Y 2001 Inorg. Chim. Acta 31518

12. Akitsu T, Komorita S and Kushi Y 1999 Bull. Chem. Soc. Jpn. 72447

13. Salmain M, Jaouen G, Rudolf B and Zakrzewski J 1999 J. Organometallic. Chem. 58998

14. Serrano J L, Zheng Y, Dilworth J R and Sánchez G 1999 Inorg. Chem. Commun. 2407

15. Serrano J L, García L, Perez J, Perez E, Vives J, Sanchez G, Lopez G, Molins E and Orpen A G 2002 Polyhedron 211589

16. Akitsu T and Einaga Y 2005 Acta Cryst. C61 m183

17. Taş $M$, Saraçoğlu $H$, Batı $H$, Çalışkan $N$ and Büyükgüngör O 2006 Z. Naturforsch. 61b 979

18. Jhon M S, Cho U, Kier L B and Eyring H 1972 Proc. Nat. Acad. Sci. USA 69121

19. Stoe\&Cie, X-Area (Version 1.18) and X-Red 32 (Version 1.04), Stoe\&Cie, Darmstadt, Germany, 2002

20. Burla M C, Caliandro R, Camalli M, Carrozzini B, Cascarano G L, De Caro L, Giacovazzo C, Polidori G and Spagna R SIR2004: A program for automatic so- lution and refinement of crystal structures $2005 \mathrm{~J}$. Appl. Crystallogr. 38381

21. Sheldrick G M 1997 SHELXL-97: Program for the refinement of crystal structures (Germany: University of Göttingen)

22. Johnson C K and Burnett M N 1997 ORTEP-III (version 1.0.2), Rep. ORNL-6895, Oak Ridge National Laboratory, Oak Ridge, TN (USA) (1996). Windows version: Farrugia L J, University of Glasgow, Glasgow, Scotland (UK)

23. Farrugia L J 1999 J. Appl. Crystallogr. 32837

24. Nakamoto K, Suzuki M, Ishiguro T, Kozuka M, Nishida Y and Kida S 1980 Inorg. Chem. 192822

25. Barraclough G, Lawrance G A and Lay P A 1978 Inorg. Chem. 173317

26. Shibahara T, Koda S and Mori M 1973 Bull. Chem. Soc. Jpn. 462070

27. McMullen S E and Hagen K S 2002 Acta Cryst. E58 m141

28. Fritch J R, Christoph G G and Schaefer W P 1973 Inorg. Chem. 122170

29. Etter M C 1990 Acc. Chem. Res. 23120 